\title{
Editorial
}

\section{Maternal and Neonatal and Child Health Priorities in Africa and Asia}

\author{
Sten H. Vermund, ${ }^{1}$ Renu Garg, ${ }^{2}$ Ying-Ru Lo, ${ }^{3}$ Emily K. Sheldon, ${ }^{1}$ and Kasonde Mwinga ${ }^{4}$ \\ ${ }^{1}$ Vanderbilt Institute for Global Health and Department of Pediatrics, Vanderbilt University School of Medicine, \\ Nashville, TN 37203, USA \\ ${ }^{2}$ WHO Regional Office for South-East Asia, New Delhi 110 002, India \\ ${ }^{3}$ WHO Regional Office for the Western Pacific, 1000 Manila, Philippines \\ ${ }^{4}$ WHO Regional Office for Africa, Brazzaville, Congo
}

Correspondence should be addressed to Sten H. Vermund; sten.vermund@vanderbilt.edu

Received 6 June 2016; Accepted 8 June 2016

Copyright (C) 2016 World Health Organization. This is an open access article distributed under the Creative Commons Attribution IGO License, which permits unrestricted use, distribution, and reproduction in any medium, provided the original work is properly cited. In any reproduction of this article there should be no suggestion that WHO endorses any specific organization or products. The use of the WHO logo is not permitted.

Immense challenges remain in the field of maternal, neonatal, and child health $(\mathrm{MNCH})$ in Africa and Asia. Vast rural poverty continues to mire both continents in patterns of risk for pregnant women and their children [1]. Especially in Africa, many nations failed to meet Millennium Development Goals 4 and 5 [2-5]. The aspirational Sustainable Development Goals also will be difficult to achieve. Still, much is being accomplished, as noted by the falling under-five mortality rates in all but a few countries [6-10].

For decades in its global health coordination role, the World Health Organization (WHO) has highlighted the vital challenges in ensuring the welfare of women and children. The maternal, neonatal, and child health $(\mathrm{MNCH})$ arena offers both preventive opportunities and obstacles; successful programmatic models show immense promise for reducing disease and suffering in low and middle income countries (LMIC). In 2015, we solicited manuscripts from global health investigators working in low and middle income countries (LMICs) in either Africa or Asia whose work would be suitably highlighted within a special 2016 issue of this journal. This commentary introduces the topics in this special issue, reflecting a diversity of topics and methodologies in the $\mathrm{MNCH}$ field.

As one reads the papers in this special issue, a number of themes emerge. The imperative to enable mothers and fathers to space and limit their children's births through contraception is presented by several investigators, a topic that is dramatized by the 7.3-billion world population as of this writing (June 2016). Similarly, the urgent need for quality improvement and equitable distribution of health care workers (HCW) is presented through various prisms. The continuing challenges of maternal sexually transmitted and other infections are evident in both Asia and Africa. The continuing threat of infectious diseases in neonates and children was also highlighted in this issue.

We hope that future articles on innovative approaches to improving maternal literacy, including health literacy and numeracy, use of modern digital devices to enhance linkage and adherence to care, combination prevention approaches, or economic empowerment of women, will be presented from Africa and Asia [11-13]. MNCH is more likely to improve when integrated development programming replaces the streaming of funds into "silos" of health or education or economic development [14-17].

The world faces perils of global climate change, loss of biodiversity, overpopulation, desertification, the rise of the megacities, and water shortages. Globalized trade and marketing are degrading healthy traditional diets with fatty, fried "fast foods" and the aggressive marketing of tobacco. With progress towards the control of infectious diseases and the rise of noncommunicable diseases in LMICs, new challenges are facing mothers and children, including obesity and 
second-hand smoke exposure. Civil strife, territorial aggression, war, and nuclear threats continue. Global educational, economic, and health inequities persist and, in some nations, worsen. Violence against women and children, suppression of women's rights, and denial of school opportunities for girls remain plagues in both continents. Yet progress towards improved $\mathrm{MNCH}$ is undeniable. The guest editors of this special issue posit two questions that build upon the reports of progress highlighted here: "How can we expand successes in women's and children's health? How can we improve the world that a new, healthier generation will inherit?"

\section{Sten H. Vermund Renu Garg Ying-Ru Lo Emily K. Sheldon Kasonde Mwinga}

\section{References}

[1] B. Victor, M. Blevins, A. F. Green et al., "Multidimensional poverty in rural mozambique: a new metric for evaluating public health interventions," PLoS ONE, vol. 9, no. 9, Article ID e108654, 2014.

[2] A. M. Kipp, M. Blevins, C. A. Haley et al., "Factors associated with declining under-five mortality rates from 2000 to 2013: an ecological analysis of 46 African countries," BMJ Open, vol. 6, no. 1, Article ID e007675, 2016.

[3] D. J. Corsi and S. V. Subramanian, "Association between coverage of maternal and child health interventions, and under-5 mortality: a repeated cross-sectional analysis of 35 sub-Saharan African countries," Global Health Action, vol. 7, no. 1, Article ID 24765, 2014.

[4] UNICEF and World Health Organization, A Decade of Tracking Progress for Maternal, Newborn and Child Survival: The 2015 Report, World Health Organization, Geneva, Switzerland, 2015, http://www.countdown2015mnch.org/reports-and-articles/2015final-report, http://www.countdown2015mnch.org/documents/ 2015Report/Countdown_to_2015_final_report.pdf.

[5] C. G. Victora, J. H. Requejo, A. J. Barros et al., "Countdown to 2015: a decade of tracking progress for maternal, newborn, and child survival," The Lancet, vol. 387, no. 10032, pp. 2049-2059, 2016.

[6] H. Wang, C. A. Liddell, M. M. Coates et al., "Global, regional, and national levels of neonatal, infant, and under-5 mortality during 1990-2013: a systematic analysis for the Global Burden of Disease Study 2013," The Lancet, vol. 384, no. 9947, pp. 957-979, 2014.

[7] N. Walker, G. Yenokyan, I. K. Friberg, and J. Bryce, "Patterns in coverage of maternal, newborn, and child health interventions: projections of neonatal and under-5 mortality to 2035," The Lancet, vol. 382, no. 9897, pp. 1029-1038, 2013.

[8] O. F. Norheim, P. Jha, K. Admasu et al., "Avoiding 40\% of the premature deaths in each country, 2010-30: review of national mortality trends to help quantify the un sustainable development goal for health," The Lancet, vol. 385, no. 9964, pp. 239252, 2015.

[9] K. Hill, D. You, M. Inoue et al., "Child mortality estimation: accelerated progress in reducing global child mortality, 19902010," PLoS Medicine, vol. 9, no. 8, Article ID e1001303, 2012.
[10] D. You, L. Hug, S. Ejdemyr et al., "Global, regional, and national levels and trends in under-5 mortality between 1990 and 2015, with scenario-based projections to 2030: a systematic analysis by the un Inter-Agency Group for Child Mortality Estimation," The Lancet, vol. 386, no. 10010, pp. 2275-2286, 2015.

[11] K. Clouse, S. R. Schwartz, A. Van Rie, J. Bassett, S. H. Vermund, and A. E. Pettifor, "High mobile phone ownership, but low Internet and email usage among pregnant, HIV-infected women attending antenatal care in Johannesburg," Journal of Telemedicine and Telecare, vol. 21, no. 2, pp. 104-107, 2015.

[12] M. H. Aliyu, M. Blevins, K. M. Megazzini et al., "Correlates of suboptimal entry into early infant diagnosis in rural North Central Nigeria," Journal of Acquired Immune Deficiency Syndromes, vol. 67, no. 1, pp. e19-e26, 2014.

[13] M. H. Aliyu, M. Blevins, C. M. Audet et al., "Integrated prevention of mother-to-child HIV transmission services, antiretroviral therapy initiation, and maternal and infant retention in care in rural north-central Nigeria: a cluster-randomised controlled trial," The Lancet HIV, vol. 3, no. 5, pp. e202-e211, 2016.

[14] L. J. Edwards, A. Moisés, M. Nzaramba et al., "Implementation of a health management mentoring program: year-1 evaluation of its impact on health system strengthening in Zambézia Province, Mozambique," International Journal of Health Policy and Management, vol. 4, no. 6, pp. 353-361, 2015.

[15] S. H. Vermund, M. Sidat, L. F. Weil, J. A. Tique, T. D. Moon, and P. J. Ciampa, "Transitioning HIV care and treatment programs in southern Africa to full local management," AIDS, vol. 26, no. 10, pp. 1303-1310, 2012.

[16] P. M. Pronyk, M. Muniz, B. Nemser et al., "The effect of an integrated multisector model for achieving the Millennium Development Goals and improving child survival in rural subSaharan Africa: a non-randomised controlled assessment," The Lancet, vol. 379, pp. 2179-2188, 2012.

[17] S. E. Arifeen, D. E. Hoque, T. Akter et al., "Effect of the Integrated Management of Childhood Illness strategy on childhood mortality and nutrition in a rural area in Bangladesh: a cluster randomised trial," The Lancet, vol. 374, no. 9687, pp. 393-403, 2009. 


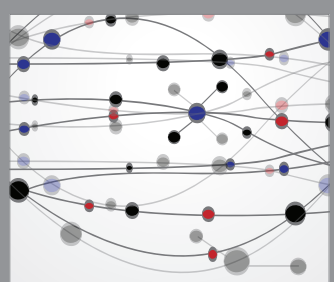

The Scientific World Journal
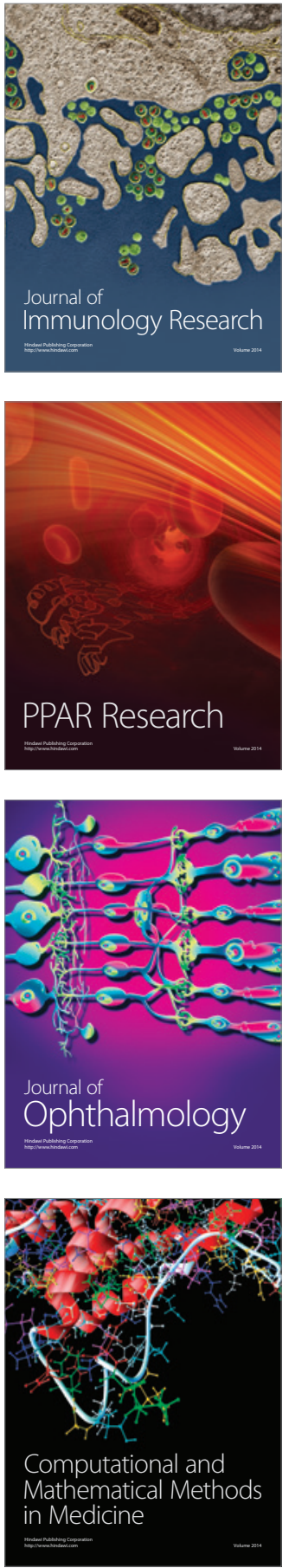

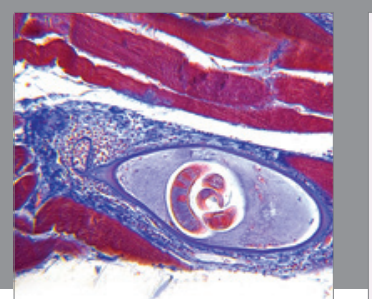

Gastroenterology Research and Practice

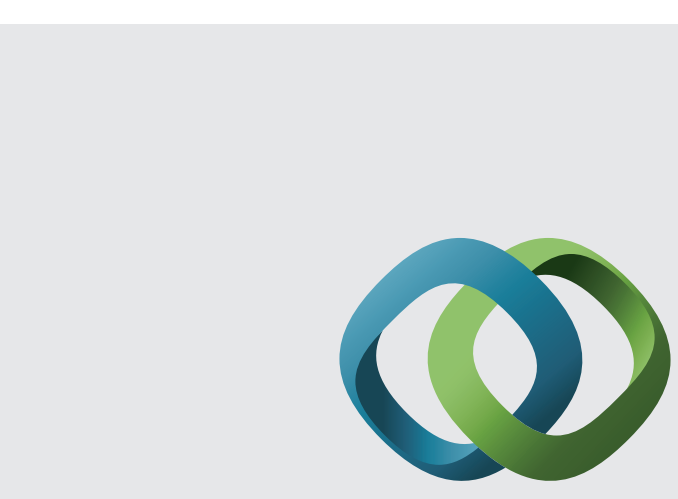

\section{Hindawi}

Submit your manuscripts at

http://www.hindawi.com
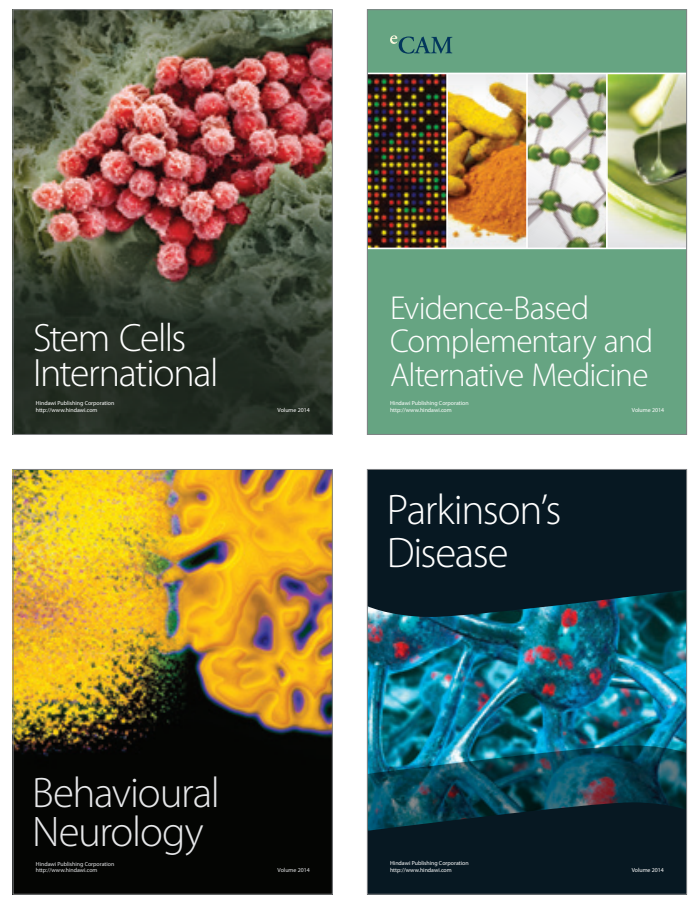
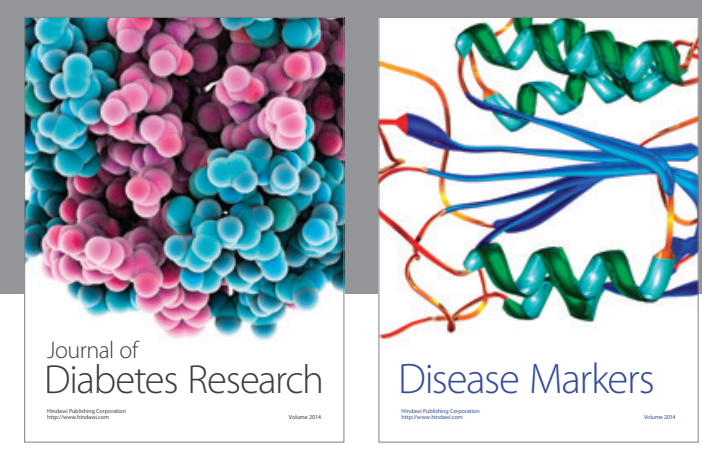

Disease Markers
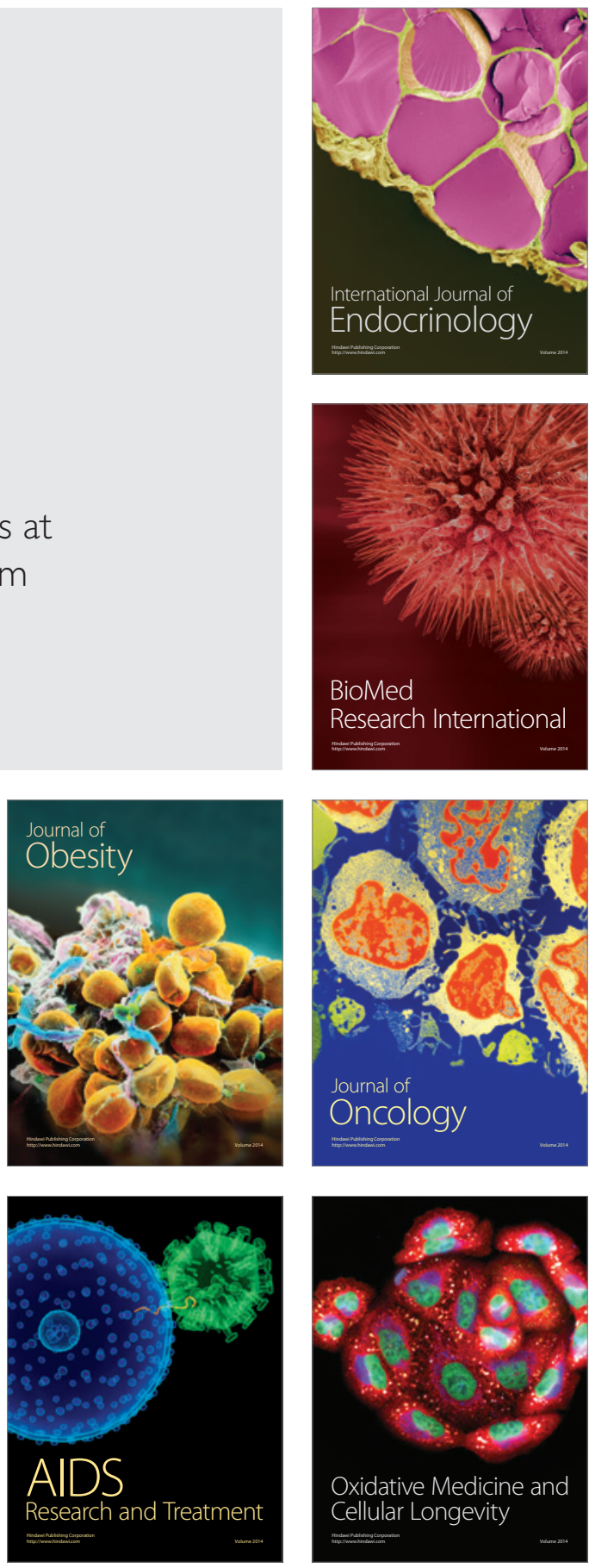